\title{
Fever after bronchoscopy: serum procalcitonin enables early diagnosis of post-interventional bacterial infection
}

\author{
Klaus Hackner ${ }^{1,2^{*}}$ D , Waltraud Riegler $r^{1,2}$, Sabin Handzhiev ${ }^{1,2}$, Rosemarie Bauer ${ }^{1,2}$, Jan Veres ${ }^{1,2}$, Manuela Speiser ${ }^{1,2}$, \\ Karin Meisinger ${ }^{1,2}$ and Peter Errhalt ${ }^{1,2}$
}

\begin{abstract}
Background: The aim of this study was to differentiate unspecific and self-limiting fever after bronchoscopy from fever due to infection by using serum procalcitonin, C-reactive protein and neutrophil count. Furthermore, frequency of fever after bronchoscopy and procedures as possible risk factors were evaluated.

Methods: Three hundred and fourteen consecutive patients were included. All bronchoscopies were performed using jet-ventilation and general anesthesia. Patients were analyzed according to interventions performed during bronchoscopy and laboratory results. Microbiological assessment was done in patients who developed fever to prove or rule out a bacterial infection.

Results: Forty-four patients showed fever within $24 \mathrm{~h}$ following bronchoscopy (14\%). A bacterial infection was proven in 11 patients with fever (3.5\%). Procalcitonin, neutrophil count and C-reactive protein were significantly higher in patients with fever after bronchoscopy compared to non-fever patients. To predict bacterial infection in the receiver operating analysis, procalcitonin had the highest area under the curve $(0.942 ; 95 \%$ confidence interval [Cl], 0.768 to 1.000; $p=<0.001$ ), followed by neutrophil count (AUC, $0.804 ; 95 \% \mathrm{Cl}, 0.606$ to $0.946 ; p=0.005$ ), whereas CRP levels where not statistically significant. Endoscopic airway recanalization was the only intervention that induced fever more frequently than all other interventions (OR 13.629).

Conclusions: Fever is frequently seen after bronchoscopy and in some cases caused by bacterial infection. Procalcitonin might be useful to distinguish a bacterial infection from unspecific self-limiting fever. Airway recanalization is a procedure that seems to induce fever significantly more often than other bronchoscopic interventions.
\end{abstract}

\section{Background}

Fever is a common phenomenon after a bronchoscopy but not always a sign of bacterial or viral infection. Since the beginning of flexible bronchoscopy in the early 1970s, a number of studies have reported transient fever within $24 \mathrm{~h}$ following the examination, estimating an incidence of $1.2-16 \%$ [1-5] for all bronchoscopic procedures.

The reason has not yet been fully discovered, however several authors described that especially bronchoalveolar lavage (BAL) may initiate an endogenous immune response. It is suggested that a systemic inflammatory response is induced, characterized by an increase in

\footnotetext{
* Correspondence: klaus.hackner@krems.lknoe.at

${ }^{1}$ Department of Pneumonology, Krems University Hospital, Mitterweg 10,

Krems, Austria

${ }^{2}$ Karl Landsteiner University of Health Science, Krems, Austria
}

circulating cytokine levels released from alveolar macrophages such as tumor necrosis factor (TNF)-alpha, interleukin (IL)-1 beta, and IL-6 [6-10]. The effect of other bronchoscopic procedures (e.g. forceps biopsy or transbronchial needle aspiration) on the release of pyrogenic mediators has not yet been widely explored.

On the other side, endoscopic examinations may be the gateway through which bacteria invade the body. There have been reports of bacteremia and sepsis following bronchoscopy in patients with impaired immune system as well as healthy patients. The frequency ranges from 0.7 to $6.5 \%$ [11-16].

Consequently, fever after bronchoscopy is not always an endogenous response to the procedure with release of pyrogenic mediators, but may be caused by bacteremia. If patients have fever after bronchoscopy, 
a further post-interventional observation seems reasonable to assess the course and to start antibiotic treatment if needed. Blood cultures are the gold standard to diagnose systemic bacterial infection. However, laboratory parameters may help predicting a bacterial infection long before the microbiological workup is available.

Circulating proinflammatory mediators such as Creactive protein (CRP) and more recently serum procalcitonin (PCT) have been suggested to be predictive for invasive bacterial infection $[17,18]$. Especially PCT was largely investigated and seams to be helpful for the decision to start antibiotic therapy in respiratory infections. [19-21] Therefore, PCT becomes a more frequently used tool in clinical routine [22-25]. The stimulating impulses for high blood levels during bacteremia and sepsis are bacterial endotoxins (e.g. LPS) and cytokines (IL1-beta, TNF-alpha). [26] Within $6 \mathrm{~h}$ after systemic inflammation was induced, PCT levels begin to rise $[27,28]$.

We hypothesize that serum biomarkers are useful tools for ruling out or predicting bacteremia in fever after bronchoscopy, next to clinical signs and symptoms.

Therefore, we performed a study to evaluate the percentage of patients with fever due to infection after bronchoscopy and the role of biomarkers to early identify the patients demanding antibiotic treatment. Furthermore, as secondary outcomes we evaluated the prevalence of fever after bronchoscopy and procedures serving as risk factors (e.g. forceps or needle biopsy).

\section{Methods}

\section{Patients and study design}

This prospective observational study was performed at the pneumonology department of the university hospital in Krems, Austria.

Every patient referred for a bronchoscopy from May 2015 to January 2016 was included in the study after screening for inclusion and exclusion criteria. If patients underwent more than one bronchoscopy within the study period only the first procedure was taken into account.

Eligible subjects were at least 18 years. A reasonable indication for a diagnostic or therapeutic bronchoscopy was mandatory, as well as informed consent by the patients to undergo bronchoscopy and related data analysis. The local institutional review board and ethics commission approved the study.

Data collection included demographics, indication for bronchoscopy, procedures, microbiological results and laboratory findings pre- and post intervention. Patients with proven bacterial infection, elevated PCT levels $(=\geq 0.5 \mathrm{ng}$ / $\mathrm{mL}$ ) or ongoing antibiotic treatment before the bronchoscopy were excluded from the study.

\section{Bronchoscopy}

Flexible, rigid or combined bronchoscopy was performed as an inpatient procedure and according to the guidelines of the European-respiratory-society [29]. All bronchoscopies were performed in jet-ventilation and the patients received general anesthesia. High frequency jet-ventilation $\left(\right.$ TwinStream $^{\mathrm{rm}}$ ) was either performed in a supraglottic approach via larynx mask using a jet-adapter [30] or via rigid bronchoscope. For general anesthesia propofol, fentanyl or remifentanil were used. Rocuronium or mivacurium were used if muscle relaxation was necessary.

Bronchoscopy in local anesthesia is rarely performed at the study center $(<5 \%$ per year) and was therefore not included in the analysis.

During the procedure, continued monitoring of vital signs and oximetry was mandatory.

For flexible bronchoscopy, several Olympus video bronchoscopes (Olympus Corp., Lake Success, NY, USA) were used. After the inspection of the bronchial tree bronchoscopic procedures were performed at the discretion of the investigators, including BAL, forceps biopsy, transbronchial needle aspiration or other interventions (airway recanalization with cryoextraction, argon plasma coagulation and forceps; brushing; bronchial-fluid sample collection; treatment of hemoptysis; stent implantation; balloon-dilatation; lung volume reduction with valves).

For the BAL procedure, $200 \mathrm{~mL}$ of prewarmed $0.9 \%$ saline were instilled into the lobe of interest and then gently aspirated, according to the guidelines [31, 32].

At the study center, overnight observation after bronchoscopy is standard-of-care. Vital signs and oximetry were monitored for $6 \mathrm{~h}$ and a chest $\mathrm{x}$-ray was performed if appropriate (e.g. after peripheral transbronchial biopsy). Adverse events were documented from the time of bronchoscopy until discharge.

\section{Measurement of temperature and laboratory parameters}

Per protocol, $6 \mathrm{~h}$ and $24 \mathrm{~h}$ after bronchoscopy, the body temperature was measured by ear thermometer. Fever was defined as an elevated body temperature of $\geq 38{ }^{\circ} \mathrm{C}$.

CRP levels, PCT levels, lymphocyte and neutrophil counts were obtained on the day prior to bronchoscopy and the day after bronchoscopy in all patients. PCT was measured using $100 \mu \mathrm{L}$ of serum by an electrochemiluminescence immunoassay (ELECSYS ${ }^{\bullet}$ PCT; Brahms AG; Henningdorf, Germany) [17, 22, 33]. The assay has a analytical sensitivity $\leq 0.02 \mathrm{ng} / \mathrm{mL}$ and a functional sensitivity $\leq 0.06 \mathrm{ng} / \mathrm{mL}$.

CRP was measured in heparin plasma using an enzyme immunoassay (CRPL3) with a detection limit of $<0,5 \mathrm{~g} /$ $\mathrm{dL}$ in heparin plasma (Hitachi Instrument 917; Roche Diagnostics, Rotkreuz, Switzerland). 


\section{Fever group}

In patients who developed fever within $24 \mathrm{~h}$ after bronchoscopy we performed a microbiological workup, including stains and cultures for bacteria and fungi in blood and bronchial fluid. Positive bacterial cultures were counted as the number of colony-forming units per milliliter, and species identification and susceptibility tests were performed according to standard methods. Bacterial infection was diagnosed in cases with positive bacteriology results in the bronchial fluid and/or blood (i.e., a culture showing a single pathogenic microorganism above a minimum concentration of $10^{4} \mathrm{cfu} / \mathrm{mL}$, excluding mouth flora).

\section{Statistical analysis}

Discrete variables are expressed as absolute number (n) and percentage (\%). Normally distributed data are shown as mean with standard deviation (SD), whereas nonnormally distributed data are presented as median with interquartile range (IQR).

For all statistical analysis, SPSS software version 20.0.0 (IBM, Armonk, NY) was used. Differences were compared by Student's $t$ test, paired $t$ test, Wilcoxon-Mann-Whitney test, chi-squared test, or Fisher's exact test, as appropriate. Differences were considered statistically significant if $P$ was $<0.05$. For correlation, spearman rho analysis was used when appropriate.

To evaluate the relationship among PCT, CRP, neutrophil count and proven bacterial infection, we constructed receiver operating characteristic (ROC) curves and determined the area under the curve (AUC). The AUC was considered to be clinically useful if it was $\geq 0.8$ [34]. All statistical tests were two-tailed.

\section{Results}

\section{Patient's characteristics}

Baseline characteristics are presented in Table 1. In total, 314 eligible patients received a bronchoscopy during the study period. The median age was 64 (interquartile range, 55 to 72 years). 114 bronchoscopies (36.3\%) were

Table 1 Baseline characteristics of the study patients

\begin{tabular}{ll}
\hline Patients characteristics & \\
\hline Number of patients & 314 \\
Female, n (\%) & $114(36.3)$ \\
Age at bronchoscopy, median (interquartile range) & $64(55-72)$ \\
Body temperature $\left({ }^{\circ} \mathrm{C}\right)$, mean (SD): & \\
Before bronchoscopy & $36.7(0.37)$ \\
After bronchoscopy, $6 \mathrm{~h}$ & $37.3(0.73)$ \\
After bronchoscopy, $24 \mathrm{~h}$ & $36.8(0.38)$ \\
Fever after bronchoscopy $\left(\mathrm{Temp} \geq 38{ }^{\circ} \mathrm{C}\right), \mathrm{n}(\%)$ & $44(14.0)$ \\
\hline
\end{tabular}

performed in female patients. The indications for bronchoscopy are shown in Table 2.

The main examination technique was flexible $(n=280$, $89.2 \%$ ), followed by combined flexible and rigid $(n=29$, $9.2 \%)$ and rigid-only bronchoscopy $(n=5,1.6 \%)$. Bronchoscopic procedures were performed at the discretion of the physician performing the exam. Forceps biopsy was performed either peripheral guided by fluoroscopy or in the central airways under visual control. Transbronchial needle aspiration was guided by endobronchial ultra-sound. Suspicion of interstitial lung diseases was the main indication for BAL, most often combined with another procedure such as peripheral forceps biopsy or transbronchial needle aspiration.

We observed 5 pneumothoraces and two major bleedings, and no deaths related to bronchoscopy.

\section{Laboratory parameters and microbiological findings in post-bronchoscopic fever}

Fever was observed in 44 patients after bronchoscopy (14\%). Table 3 represents characteristics of laboratory results in the fever and non-fever cohort. Gender and age were almost equally distributed. Patients in the fever cohort had a slightly higher but not significant level of CRP, PCT and neutrophil count before bronchoscopy compared to the non-fever cohort. There is a consistent elevation of this parameters after bronchoscopy in both cohorts, nevertheless mean levels of CRP (11.03 $\mathrm{mg} / \mathrm{dL})$, neutrophil count $(9.21 \mathrm{G} / \mathrm{L})$ and PCT $(0.78 \mathrm{ng} / \mathrm{mL})$ were significantly higher in the fever group ( $\mathrm{p}=<0.001, p=0.001, p=<0.001)$. There was no difference in lymphocyte count in both cohorts before

Table 2 Indications for 314 bronchoscopies

\begin{tabular}{ll}
\hline Underlying indication & Patients \\
\hline Airway stenosis, suspected foreign body & $5(1.6)$ \\
Atelectasis & $8(2.5)$ \\
Bronchiectasis & $2(0.6)$ \\
Hemoptysis of unknown origin & $12(3.8)$ \\
Emphysema, lung volume reduction & $1(0.3)$ \\
Unclear lymphadenopathia & $18(5.8)$ \\
Suspected mucoid impaction & $1(0.3)$ \\
Suspected endobronchial polyp & $2(0.6)$ \\
Indication for airway recanalization & $15(4.8)$ \\
Indication for stent-implantation & $2(0.6)$ \\
Suspected interstitial lung disease & $51(16.3)$ \\
Suspected malignant tumor & $148(47.2)$ \\
Suspected pulmonary metastasis & $10(3.2)$ \\
Suspected mycobacteriosis other than tuberculosis & $6(1.9)$ \\
Suspected tuberculosis & $16(5.1)$ \\
Unclear radiologic infiltrative findings & $17(5.4)$ \\
\hline
\end{tabular}


Table 3 Comparison of laboratory results of patients with fever and without fever after bronchoscopy

\begin{tabular}{|c|c|c|c|c|}
\hline & All $(n=314)$ & Fever $(n=44)$ & No fever $(n=270)$ & $P$ value \\
\hline Male gender, $n(\%)$ & $200(63.7)$ & $30(68.2)$ & $170(62.5)$ & n.s. \\
\hline Age at bronchoscopy, median (interquartile range) & $64(55-72)$ & $64(53-73)$ & $64(56-72)$ & n.s. \\
\hline \multicolumn{5}{|l|}{ Laboratory findings before bronchoscopy ${ }^{\mathrm{a}}$, mean (SD) } \\
\hline C-reactive protein (mg/dL) & $2.58(4.58)$ & $5.04(6.21)$ & $2.18(4.12)$ & n.s. \\
\hline Absolute neutrophil count (G/L) & $5.83(2.63)$ & $6.32(3.66)$ & $5.75(2.42)$ & n.s. \\
\hline Absolute lymphocyte count (G/L) & $1.61(0.71)$ & $1.47(0.59)$ & $1.63(0.72)$ & n.s. \\
\hline Procalcitonin (ng/mL) & $0.11(0.37)$ & $0.26(0.21)$ & $0.08(0.22)$ & n.s. \\
\hline \multicolumn{5}{|l|}{ Laboratory findings after bronchoscopy ${ }^{\mathrm{b}}$, mean (SD) } \\
\hline C-reactive protein (mg/dL) & $4.12(5.06)$ & $11.03(7.34)$ & $3.06(3.56)$ & $<0.001$ \\
\hline Absolute neutrophil count (G/L) & $6.85(3.21)$ & $9.21(4.41)$ & $6.51(2.84)$ & 0.001 \\
\hline Absolute lymphocyte count (G/L) & $1.72(0.73)$ & $1.46(0.50)$ & $1.76(0.75)$ & n.s. \\
\hline Procalcitonin (ng/mL) & $0.19(0.73)$ & $0.78(1.79)$ & $0.11(0.28)$ & 0.029 \\
\hline Change of C-reactive protein (mg/dL), mean (SD) & $+1.54(3.39)$ & $+5.82(4.79)$ & $+0.88(2.54)$ & $<0.001$ \\
\hline Change of Procalcitonin ( $\mathrm{ng} / \mathrm{mL})$, mean (SD) & $+0.08(0.38)$ & $+0.47(0.86)$ & $+0.03(0.23)$ & 0.002 \\
\hline Change of neutrophil count (G/L), mean (SD) & $+1.02(3.17)$ & $+2.88(4.88)$ & $+0.72(2.68)$ & 0.006 \\
\hline Change of lymphocyte count (G/L), mean (SD) & $+0.10(0.49)$ & $-0.01(0.33)$ & $+0.12(0.52)$ & n.s. \\
\hline Elevated procalcitonin ( $\geq 0,5 \mathrm{ng} / \mathrm{mL}), \mathrm{n}(\%)$ & $16(5.1)$ & $13(29.5)$ & $3(0.1)$ & $<0.001$ \\
\hline
\end{tabular}

${ }^{a}$ The laboratory results were obtained on the day before bronchoscopy

${ }^{\mathrm{b}}$ The laboratory results were obtained $12-24 \mathrm{~h}$ after the bronchoscopy

${ }^{\dagger}$ Fisher's exact test was applied

and after bronchoscopy. Mean PCT was elevated in both cohorts after bronchoscopy compared to the values before bronchoscopy, but the increase was significantly higher in the fever cohort $(0.78 \mathrm{ng} / \mathrm{mL} ; p=$ 0.029). In total, 13 patients (29.5\%) in the fever cohort and 3 patients $(0.1 \%)$ in the non-fever cohort showed values above $0,5 \mathrm{ng} / \mathrm{mL}$ which represents the upper limit for healthy persons.

There was a moderate correlation between PCT and CRP levels in the fever cohort (Spearman rho $=0.472$; $p=<0.001)$ and between PCT and neutrophil count (Spearman rho $=0.513 ; \mathrm{p}=<0.001$ ). There was no correlation between $\mathrm{PCT}$ and lymphocyte count $(p=$ 0.124).

To identify the main outcome parameter, microbiological workup was performed in the fever cohort. In 11 patients (3.5\% of the study population) a bacterial infection was diagnosed by positive microbiological culture result in the bronchial fluid and/or blood. A detailed overview of these patients is given in Table 4. All of the

Table 4 Documentation of post-interventional procalcitonin level and microbiological findings in patients with fever and proven bacterial infection after bronchoscopy

\begin{tabular}{lll}
\hline Noteable endoluminal findings & Microbiological findings & PCT, ng/ml \\
\hline Purulent bronchial fluid & Klebsiella pneumoniae - BF & 1.0 \\
- & E.coli - BF, sputum & 1.1 \\
- & Mycobacterium tuberculosis - BF, pleural fluid & 1.4 \\
- & Haemophilus influenzae - BF & 1.4 \\
Purulent bronchial fluid & P. aeruginosa - BF, BC & 1.3 \\
Exophytic stenosis, poststenotic pneumonia & S. pneumoniae - BF, BC & 11.1 \\
purulent bronchial fluid & E. coli - BF, BC & 4.4 \\
Exophytic stenosis & Haemophilus influenzae - BF & 1.8 \\
Mucus plug, purulent bronchial fluid & S. pneumoniae - BF & 0.2 \\
Purulent bronchial fluid & P. aeruginosa - BF & 0.3 \\
Poststenotic purulent bronchial fluid & S. pyogenes - BF & 2.6 \\
\hline
\end{tabular}

BF Bronchial fluid

$B C$ Blood culture

PCT Procalcitonin level (on the day after bronchoscopy) 
patients with post interventional bacterial infection received empiric antibiotic or tuberculostatic treatment. Final culture reports and resistograms did not necessitate changes in the treatment in all patients.

In 33 patients with fever after bronchoscopy we could not find evidence of bacterial infection. Therefore, they were regarded to have nonspecific fever.

The fever patients were divided into those with proven bacterial infection and those with nonspecific fever and the laboratory findings were compared, as seen in Table 5 . While there was a statistically significant difference in neutrophil counts $(p=0.014)$ and PCT $(p=$ $<0.001)$, CRP levels and lymphocyte counts showed no significant difference (determined by Wilcoxon-MannWhitney test).

To determine the diagnostic value of laboratory parameters to predict a bacterial infection after bronchoscopy we performed ROC analysis (Fig. 1) in all patients with post-bronchoscopic fever $(n=44)$. PCT levels had the highest AUC $(0.942 ; 95 \% \mathrm{CI}, 0.768$ to $1.000 ; p<$ 0.001), followed by neutrophil counts (AUC, 0.804; $95 \%$ CI, 0.606 to $0.946 ; p=0.005$ ). The AUC was not statistically significant for CRP levels (AUC, 0.729; 95\% CI, 0.492 to $0.838 ; p=0.094$ ).

Sensitivity, specificity, Youden index and positive and negative likelihood ratio point estimates for neutrophil counts and PCT are presented in Table 6. At the threshold value of $10.0 \mathrm{G} / \mathrm{L}$, neutrophil levels had a sensitivity of $72 \%$ and a specificity of $79 \%$. PCT levels showed a specificity of $84 \%$ and a sensitivity of $81 \%$ at the threshold value of $0.5 \mathrm{ng} / \mathrm{mL}$.

\section{Distribution of bronchoscopic procedures in the two cohorts}

The fever group was compared with the non-fever group to evaluate procedures as potential risk factor for post-interventional fever. Performing a forceps biopsy (odds ratio [OR] 0.513; 95\% confidence interval [CI], 0.253 to $1.040: p=0.061$ ) or transbronchial needle aspiration alone (OR 1.588; 95\% CI, 0.505 to 4.990: $p=$ 0.425) showed no evidence of being an independent risk factor. Performing a BAL during bronchoscopy was no significant risk factor (OR $0.474 ; 95 \% \mathrm{CI}, 0.162$ to
1.390: $p=0.165$ ), as well as performing a bronchoscopy without a BAL (OR 0.540; 95\% CI, 0.262 to 1.116: $p=$ 0.093).

There was no significant difference in the mean value of recovery fluid when BAL was performed $(71.50 \mathrm{ml}$ in the fever cohort and $76.60 \mathrm{ml}$ in the non-fever cohort), or the mean number of specimen taken at forceps biopsy (4 in both cohorts) or transbronchial needle aspiration (3 in both cohorts).

Other procedures like brushing and bronchial-fluid sample collection, treatment of hemoptysis, stent implantation, balloon dilatation, airway inspection or endoscopic lung volume reduction with valves failed to show significance for post-bronchoscopic fever. Furthermore, various combinations of different procedures failed to show significantly more fever.

The only intervention associated with significantly higher frequency of fever was airway recanalization with forceps and argon plasma coagulation. From a total of 15 recanalization procedures, 10 patients developed fever (66.7\%), with an OR of 13.629 (95\% CI, 4.321 to 42.983: $p=<0.001)$.

\section{Discussion}

This is the first prospective study using inflammatory biomarkers to rule out or prove a bacterial infection when fever after bronchoscopy in general anesthesia occurs.

The prevalence of post-bronchoscopic fever was $14 \%$. These finding is in line with previous studies, showing an incidence of fever after a bronchoscopy in 1.2-16\% $[1-4,35]$.

The percentage of infectious fever after bronchoscopy was $3.5 \%$.

Inflammatory biomarkers might be a useful approach to decide for an antibiotic therapy long before culture results would be available $[17,36]$. The present findings illustrate that PCT levels are significantly higher in patients with a proven bacterial infection, when fever after bronchoscopy occurs. Interestingly, a rise of neutrophil granulocytes was another significant indicator for bacterial infection, proving an adequate immune response to the infection. The AUC for both laboratory tests showed

Table 5 Laboratory parameters after bronchoscopy in patients having fever caused by proven bacterial infection and patients with unspecific fever

\begin{tabular}{|c|c|c|c|c|}
\hline & Fever + proven bacterial infection $(n=11)$ & Unspecific fever $(n=33)$ & All $(n=44)$ & $p$-Value \\
\hline CRP, mg/dL (SD) & $14.76(6.81)$ & $10.03(7.17)$ & $11.03(7.34)$ & n.s. \\
\hline Neutrophils, G/L (SD) & $13.11(5.74)$ & $7.93(3.01)$ & $9.21(4.41)$ & $0.014^{\mathrm{a}}$ \\
\hline Lymphocytes, G/L (SD) & $1.21(0.60)$ & $1.55(0.49)$ & $1.46(0.50)$ & n.s. \\
\hline Procalcitonin, ng/mL, (SD) & $2.41(3.10)$ & $0.24(0.27)$ & $0.78(1.79)$ & $<0.001^{\mathrm{a}}$ \\
\hline
\end{tabular}

Wilcoxon-Mann-Whitney test was applied 


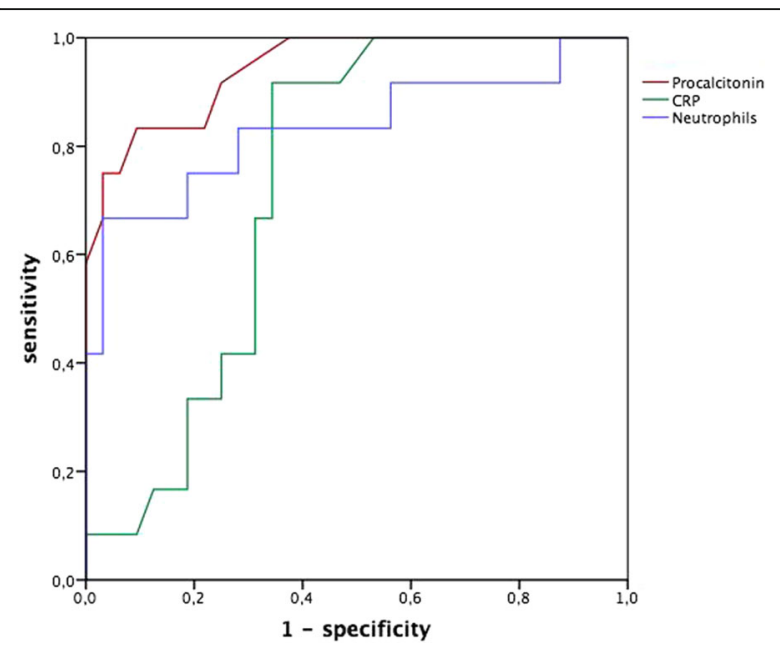

Fig. 1 ROC analysis for prediction of bacterial infection causing fever after bronchoscopy: Procalcitonin level (AUC, 0.942; 95\% confidence interval [CI], 0.768 to $1.000 ; p<0.001)$, Absolute Neutrophil count (AUC, $0.804 ; 95 \% \mathrm{Cl}, 0.606$ to $0.946 ; p=0.005$ ) and CRP levels (AUC, $0.729 ; 95 \% \mathrm{Cl}, 0.492$ to $0.838 ; p=0.094$ ) are given

very valuable results, therefore both of them should be considered in the decision making process.

A second outcome of this study was the investigation of different bronchoscopic procedures, serving as risk factor for post-bronchoscopic fever. Airway recanalization was the only intervention associated with significantly higher rates of fever in this study. We hypothesize that the destruction of tissue is causing a local and systemic inflammatory response. Furthermore, the disruption of epithelial integrity is a potential gateway for pathogens. Therefore, continuous monitoring after recanalization is advisable, with rapid counter-measures when signs of pulmonary bacterial infection or elevated biomarkers are noticed. In

Table 6 Point estimates for absolute blood neutrophil count and procalcitonin to diagnose an underlying bacterial infection when fever after bronchoscopy occurs

\begin{tabular}{|c|c|c|c|c|c|}
\hline Variables & Sensitivity & Specificity & LHR+ & LHR- & J \\
\hline \multicolumn{6}{|c|}{ Blood neutrophils, G/L } \\
\hline 5.0 & $90 \%$ & $16 \%$ & 1.07 & 0.63 & 0.06 \\
\hline 10.0 & $72 \%$ & $79 \%$ & 3.43 & 0.35 & 0.51 \\
\hline 12.0 & $63 \%$ & $91 \%$ & 7.00 & 0.41 & 0.54 \\
\hline \multicolumn{6}{|c|}{ Procalcitonin, ng/mL } \\
\hline 0.1 & $98 \%$ & $60 \%$ & 2.45 & 0.03 & 0.58 \\
\hline 0.2 & $90 \%$ & $73 \%$ & 3.33 & 0.14 & 0.63 \\
\hline 0.5 & $81 \%$ & $84 \%$ & 5.06 & 0.23 & 0.65 \\
\hline 1.0 & $72 \%$ & $97 \%$ & 2.40 & 0.29 & 0.69 \\
\hline
\end{tabular}

LHR+ Positive likelihood ratio

$L H R$ - Negative likelihood ratio

$J$ Youden Index this subgroup (airway-recanalization) fever is frequent (66.7\%) and early identification of patients requiring antibiotic therapy could be of clinical and economic benefit. The measurement of PCT the day after bronchoscopy could guide the decision of antibiotic treatment vs. discharge.

Other bronchoscopic interventions, such as forceps biopsy, transbronchial needle aspiration, or various combinations of these procedures did not cause fever. This finding is in line with several other studies [1, 3-5]. Despite previous reports [6-10], BAL did not provoke higher rates of fever.

Several limitations should be noted. First, we cannot provide information of complete microbiological workup for some patients without fever after bronchoscopy, because bronchial fluid collection was not performed in all of them.

Second, we did not implement multiplex polymerasechain-reaction (PCR) technologies for the diagnosis of post-bronchoscopic infections, as they were not available during the study period at the study site. We suggest complete microbiological workup and the use of PCR technologies for further studies investigating this topic.

Third, we have evaluated clinical and laboratory parameters in regard to their diagnostic value on the day after bronchoscopy (not at the initiation of symptoms), and the kinetics of the biomarkers have not yet been analyzed.

Fourth, we did not evaluate procedure time or the impact of the used anesthetics.

Another limitation is the monocentric design. All included bronchoscopies were performed in jetventilation according to the clinics standard operating procedures. Although ventilation or anesthesia is unlikely to affect the outcome of this study, we recommend further multicenter approaches on this topic with inclusion of different ventilation, local anesthesia and evaluation of procedure time.

\section{Conclusions}

In summary, our findings indicate that PCT and blood neutrophil counts seem to be useful tools to guide diagnostic and early therapeutic decisions for an underlying bacterial infection when patients develop fever after bronchoscopy,

Furthermore, endoscopic airway recanalization tends to be a risk factor for post-bronchoscopic fever.

\section{Abbreviations}

AUC: Area under the curve; BAL: Bronchoalveolar lavage; Cl: Confidence interval; CRP: C-reactive protein; IQR: Interquartile range; OR: Odds ratio; PCR: Polymerase chain reaction; PCT: Procalcitonin; ROC: Receiver operating characteristics; SD: Standard deviation

Aknowledgments Not applicable. 


\section{Funding}

Not applicable.

\section{Availability of data and materials}

Data cannot be made publicly available for ethical reason as the data are patient data.

\section{Authors' contributions}

KH: study design, data analysis, data interpretation and manuscript preparation; WR: study design, data collection and data interpretation; SH: study design, data collection and data interpretation; RB: study design, data collection and data interpretation; JV: study design, data collection and dat interpretation KM: study design, data collection and data interpretation MS: study design, data collection and data interpretation PE: study design, data analysis, data interpretation, manuscript preparation and supervision of the study. All authors read and approved the final manuscript.

\section{Ethics approval and consent to participate}

The local institutional review board and ethics commission (Ethics Committee for Lower Austria) approved the study. Every participating patient obtained written informed consent.

\section{Consent for publication}

The corresponding author takes responsibility for the content of the manuscript, including the data and analysis.

\section{Competing interests}

All authors declare that they have no competing interests.

\section{Publisher's Note}

Springer Nature remains neutral with regard to jurisdictional claims in published maps and institutional affiliations.

\section{Received: 6 August 2017 Accepted: 17 November 2017}

Published online: 28 November 2017

\section{References}

1. Pereira WJ, Kovnat DM, Snider GL. A prospective cooperative study of complications following flexible fiberoptic bronchoscopy. Chest. 1978; 73(6):813-6

2. Pereira W, Kovnat DM, Khan MA, lacovino JR, Spivack ML, Snider GL. Fever and pneumonia after flexible fiberoptic bronchoscopy. Am Rev Respir Dis. 1975;112(1):59-64

3. Um SW, Choi CM, Lee CT, Kim YW, Han SK, Shim YS, Yoo CG. Prospective analysis of clinical characteristics and risk factors of postbronchoscopy fever. Chest. 2004:125(3):945-52.

4. Witte MC, Opal SM, Gilbert JG, Pluss JL, Thomas DA, Olsen JD, Perry ME. Incidence of fever and bacteremia following transbronchial needle aspiration. Chest. 1986;89(1):85-7.

5. Kanemoto K, Satoh H, Ishikawa H, Ishikawa S, Ohtsuka M, Sekizawa K. Prospective study of fever and pneumonia after flexible fiberoptic bronchoscopy in older people. J Am Geriatr Soc. 2006;54(5):827-30.

6. Terashima T, Amakawa K, Matsumaru A, van Eeden S, Hogg JC, Yamaguch K. BAL induces an increase in peripheral blood neutrophils and cytokine levels in healthy volunteers and patients with pneumonia. Chest. 2001; 119(6):1724-9.

7. Krause A, Hohberg B, Heine F, John M, Burmester GR, Witt C. Cytokines derived from alveolar macrophages induce fever after bronchoscopy and bronchoalveolar lavage. Am J Respir Crit Care Med. 1997:155(5):1793-7.

8. Nelson ME, Wald TC, Bailey K, Wesselius L. Intrapulmonary cytokine accumulation following BAL and the role of endotoxin contamination. Chest. 1999:115(1):151-7.

9. Standiford TJ, Kunkel SL, Strieter RM. Elevated serum levels of tumor necrosis factor-alpha after bronchoscopy and bronchoalveolar lavage. Chest. 1991;99(6):1529-30

10. Von Essen SG, Robbins RA, Spurzem JR, Thompson AB, McGranaghan SS, Rennard SI. Bronchoscopy with bronchoalveolar lavage causes neutrophil recruitment to the lower respiratory tract. Am Rev Respir Dis. 1991;144(4): 848-54

11. Timms RM, Harrell JH. Bacteremia related to fiberoptic bronchoscopy. A case report. Am Rev Respir Dis. 1975;111(4):555-7.
12. Beyt BEJ, King DK, Glew RH. Fatal pneumonitis and septicemia after fiberoptic bronchoscopy. Chest. 1977:72(1):105-7.

13. Picard E, Schwartz S, Goldberg S, Glick T, Villa Y, Kerem E. A prospective study of fever and bacteremia after flexible fiberoptic bronchoscopy in children. Chest. 2000;117(2):573-7.

14. Yigla M, Oren I, Bentur L, Solomonov A, Elias N, Altshuler R, Rubin AE, Lejbkowicz F. Incidence of bacteraemia following fibreoptic bronchoscopy. Eur Respir J. 1999;14(4):789-91.

15. Gillis S, Dann EJ, Berkman N, Koganox Y, Kramer MR. Fatal Haemophilus influenzae septicemia following bronchoscopy in a splenectomized patient. Chest. 1993:104(5):1607-9.

16. Sharif-Kashani B, Shahabi P, Behzadnia N, Mohammad-Taheri Z, Mansouri D, Masjedi MR, Zargari L, Salimi Negad L. Incidence of fever and bacteriemia following flexible fiberoptic bronchoscopy: a prospective study. Acta medica Iranica 2010:48(6):385-8.

17. Wacker C, Prkno A, Brunkhorst FM, Schlattmann P. Procalcitonin as a diagnostic marker for sepsis: a systematic review and meta-analysis. Lancet Infect Dis. 2013;13(5):426-35

18. Harbarth S, Holeckova K, Froidevaux C, Pittet D, Ricou B, Grau GE, Vadas L, Pugin J, Geneva Sepsis N. Diagnostic value of procalcitonin, interleukin-6, and interleukin-8 in critically ill patients admitted with suspected sepsis. Am J Respir Crit Care Med. 2001;164(3):396-402.

19. Christ-Crain M, Stolz D, Bingisser R, Muller C, Miedinger D, Huber PR Zimmerli W, Harbarth S, Tamm M, Muller B. Procalcitonin guidance of antibiotic therapy in community-acquired pneumonia: a randomized trial. Am J Respir Crit Care Med. 2006;174(1):84-93.

20. Christ-Crain M, Jaccard-Stolz D, Bingisser R, Gencay MM, Huber PR, Tamm M, Muller B. Effect of procalcitonin-guided treatment on antibiotic use and outcome in lower respiratory tract infections: cluster-randomised, single-blinded intervention trial. Lancet. 2004; 363(9409):600-7.

21. Stolz D, Stulz A, Muller B, Gratwohl A, Tamm M. BAL neutrophils, serum procalcitonin, and C-reactive protein to predict bacterial infection in the immunocompromised host. Chest. 2007:132(2):504-14.

22. Schuetz P, Christ-Crain M, Muller B. Procalcitonin and other biomarkers to improve assessment and antibiotic stewardship in infections-hope for hype? Swiss Med Wkly. 2009;139(23-24):318-26.

23. Schuetz P, Albrich W, Mueller B. Procalcitonin for diagnosis of infection and guide to antibiotic decisions: past, present and future. BMC Med. 2011;9:107

24. Matthaiou DK, Ntani G, Kontogiorgi M, Poulakou G, Armaganidis A, Dimopoulos G, An ESICM. Systematic review and meta-analysis of procalcitonin-guided antibiotic therapy algorithms in adult critically ill patients. Intensive Care Med. 2012;38(6):940-9.

25. Gilbert DN. Procalcitonin as a biomarker in respiratory tract infection. Clinical infectious diseases : an official publication of the Infectious Diseases Society of America. 2011:52(Suppl 4):S346-50.

26. Gilbert DN. Use of plasma procalcitonin levels as an adjunct to clinical microbiology. J Clin Microbiol. 2010:48(7):2325-9.

27. Pfafflin A, Schleicher E. Inflammation markers in point-of-care testing (POCT) Anal Bioanal Chem. 2009:393(5):1473-80.

28. Brunkhorst FM, Heinz U, Forycki ZF. Kinetics of procalcitonin in iatrogenic sepsis. Intensive Care Med. 1998:24(8):888-9.

29. Bolliger CT, Mathur PN, Beamis JF, Becker HD, Cavaliere S, Colt H, DiazJimenez JP, Dumon JF, Edell E, Kovitz KL, et al. ERS/ATS statement on interventional pulmonology. European Respiratory Society/American Thoracic Society. Eur Respir J. 2002;19(2):356-73.

30. Veres J, Slavei K, Errhalt P, Seyr M, Ihra G. The Veres adapter: clinical experience with a new device for jet ventilation via a laryngeal mask airway during flexible bronchoscopy. Anesth Analg. 2011;112(3):597-600.

31. Clinical guidelines and indications for bronchoalveolar lavage (BAL): Report of the European Society of Pneumology Task Group on BAL. The European respiratory journal 1990, 3(8):937-976.

32. Meyer KC, Raghu G, Baughman RP, Brown KK, Costabel U, du Bois RM, Dren M, Haslam PL, Kim DS, Nagai S, et al. An official American Thoracic Society clinical practice guideline: the clinical utility of bronchoalveolar lavage cellular analysis in interstitial lung disease. Am J Respir Crit Care Med. 2012; 185(9):1004-14

33. Linscheid P, Seboek D, Schaer DJ, Zulewski H, Keller U, Muller B. Expression and secretion of procalcitonin and calcitonin gene-related peptide by 
adherent monocytes and by macrophage-activated adipocytes. Crit Care Med. 2004;32(8):1715-21.

34. Metz CE. Basic principles of ROC analysis. Semin Nucl Med. 1978;8(4):283-98.

35. Suratt PM, Smiddy JF, Gruber B. Deaths and complications associated with fiberoptic bronchoscopy. Chest. 1976;69(6):747-51.

36. Persson L, Engervall P, Magnuson A, Vikerfors T, Soderquist B, Hansson LO, Tidefelt U. Use of inflammatory markers for early detection of bacteraemia in patients with febrile neutropenia. Scand J Infect Dis. 2004;36(5):365-71.

Submit your next manuscript to BioMed Central and we will help you at every step:

- We accept pre-submission inquiries

- Our selector tool helps you to find the most relevant journal

- We provide round the clock customer support

- Convenient online submission

- Thorough peer review

- Inclusion in PubMed and all major indexing services

- Maximum visibility for your research

Submit your manuscript at www.biomedcentral.com/submit 